Dr. M. J. H. Smeets en J. H. Meihuizen, „Beknopte Belastinggids” 7e druk. Uitgave L. J. van Veen Uitgeversmij. A'dam, prijs ing. $f 4.90$. gecart. $f 5.75$.

Dis. M. J. van der Ploeg. "De administratie als hulpmiddel bij het bedrijfsbeheer. Uitgave N. Samson N.V. Alphen a/d Rijn, prijs geb. f 5.25 .

Drs. S. C. Bakkenist en Drs. W. J. v. d. Woestijne, .De positie van het Fabrikanten-merkartikel in de Kruideniersbranche". Uitgave C. Misset Uitgeversmij. Doetinchem, prijs ing. f 5.-.

\title{
SYSTEMATIEK VAN DE REPERTORIA
}

\section{Van de Redactie}

$\mathrm{Nu}$ de Centrale Documentatiedienst inzake Bedrijfsorganisatie zich met de verzorging van de Repertoria heeft belast en deze dus weer regelmatig in ons tijdschrift zullen worden opgenomen, besloot de redactie een herdruk van de systematiek van de Repertoria op te nemen, teneinde den lezers het raadplegen en rangschikken van de verschillende excerpten gemakkelijker te maken.

\section{A. ACCOUNTANCY}

I. Algemeen

II. Het accountantsberoep

1. Algemeen

2. Geschiedenis en ontwikkeling

3. Opleiding, examen, scholing

4. Organisatie en wettelijke regeling van het beroep

III. Leer van de inrichting

1. Algemeen

2. Stelsels en methoden van boekhouding

3 Techniek van boekhouding. administratieve en mechanische hulpmiddelen

4. Interne controle

IV. Leer van de contröle

1. Algencen

2. Taak en verantwoordelijkheid van den accountant als controleur; de verklaring

3. Techniek van de algemeene contröle en van bijzondere onderzoekingen

4. Organisatie van den contrôle-arbeid

\section{B. BEDRIJESHUISHOUDKUNDE}

\section{a. ALGEMEENE BEDRIJFSHUISHOUDKUNDE}

I. Algemeen

II. Bedrijfshuishoudkunde als wetenschap

1. Algemeen

2. Doelstelling, werkmethode, verhouding tot andere wetenschappen

3. Geschicdenis

4. Onderwijs

III. Waarnemingsmiddelen

1. Algemeen

2. Statistiek en documentatie

3. Koopmansboekhouding

4. Kameralistiek

5. Economische voorlichting 
IV. Leer van den kostprijs en de prijsvorming

1. Algemeen

2. Waarde en kostprijs

2a. Waarde en kostprijs, grondslagen en methoden der kostenverdeeling

2b. Kostprijsboekhouding, voor- en nacalculatie

2c. Bedrijfsdrukte

2d. Differentieele kosten

2e. Waardebepaling voor de balans, wettelijke en fiscale regeling

3. Rentekosten

4. Arbeidskosten

5. Kosten van grond- en hulpstoffen

6. Kosten der duurzame productie-middelen. afschrijvingen

7. Kosten van diensten, belastingen

8. Ondernemerspremie, winst, goodwill

9. Prijs, prijspolitiek, tarieven, prijsregeling, monopolie

V. Leer van de Finasciering

1. Algemeen

2. Grondslagen en methoden der financiering; beleggingsvraagstukken

3. Kapitaal- en geldmarkt

3a. Vraagstukken van kapitaal- en geldmarkt, effecten- en kredietvormen

$3 \mathrm{~b}$. het aandeel

3c. het preferente aandeel

$3 \mathrm{~d}$. de obligatie

4. Afnemers- en leverancierskrediet

5. Bijzondere financieringen

5a. Gemeenschapskrediet

5b. Middenstandskrediet

5c. Afbetalingskrediet

5d. Overige bijzondere financieringen, w.o. industriefinanciering

6. Reservevorming, dividendpolitiek

7. Rendabiliteits- en liquiditeitsvraagstukken

8. Financieele reorganisatie

VI. Leer van de Organisatie

1. Algemeen

2. Verbijzondering, differentieering en specialiseering, proportionaliteit

3. Private en sociale voortbrenging, ordening

4. Vereenvormiging der voortbrenging

5. Concentratie, trusts en kartels, grootte der bedrijfseenheid

6. Marktvorming en marktorganisatie

7. Voorraadvorming, termijnhandel

8. Vestigingsplaats

9. Taak en plaats van den zelfstandigen handel, grossierderij, groothande\}, detailhandel, warenhuis, het middenstandsvraagstuk

10. Coöperatie

11. Reclame

12. Marktanalyse, conjunctuuranalyse en conjunctuurpolitiek

13. Grondslagen van de inwendige organisatie van het bedrijf; rationalisatie in het algemeen en efficientie

14. Ondernemingsvormen

15. In- en verkooppolitiek, merkartikel

16. Bedrijfsleiding, bestuur en contröle

17. Accountant, ingenieur

18. Bedrijfsbegrooting, kostenstandaards, efficientiestandaards

19. Planning, routing, kettingarbeid, organisatie van de technische inrichting

20. Magazijnorganisatie

21. Verkooporganisatie

22. Inkooporganisatie

23. Kantoororganisatie

VII. Leer van de Arbeidsvocrwaarden

1. Algemeen

2. De hoogte van het loon, loon en prestatie, gezinsloon, loon en verkeerswaarde

3. Loonpolitiek, loonstelsels, winstdeeling, bedrijfsmedebezit

4. De strijd om de arbeidsvoorwaarden, vakvereenigingen, staking, medezeggenschap, bindende regelingen 
5. Psychotechniek en arbeidspsychologie, tijd- en bewegingsstudiën

,6. Arbeidstijd

7. Opleiding, scholing, oefening, handwerk

8. Arbeidersverzorging

9. Sociale verzekering

10. Werkloosheid, arbeidsbemiddeling

\section{b. BIJZONDERE BEDRIJVEN}

\section{Extractieve bedrijven}

1. Algemeen

2. Goud en andere edele metalen

3. IJzer, tin en andere onedele metalen

4. Petroleum

5. Steengroeven

6. Steenkolenmijnen

7. Veenderijen

8. Winning van kalk, mergel, asphalt, zand, grint

9. Zoutwinning

10. Diverse extractieve bedrijuen

II. Boschexploitatie en houtaankap

III. Visscherij

IV. Landbouw - en Cultutrbedrijven

1. Algemeen

2. Landbouw en veeteelt, tuinbouw, bloemencultuur

3. Suikercultutir

4. Koffiecultuur

5. Rijstcultuur

6. Theecultuur

7. Rubbercultuur

8. Cacaocultuur

9. Tabakscultuur

10. Diverse koloniale cultures

V. Industrie

1. Algemeen, industrialisatie

2. Hoogovens en ruwijzer

3. Machinefabrieken en metaalconstructie

4. Metaalwaren en metaalbewerking

5. Electrotechniek en instrumenten

6. Edelmetaal, diamant en kunstnijverheid

7. Houtbewerkings- en meubelindustrie

8. Scheepsbouw (en industiie voor den bouw van vervoermiddelen in het algemeen)

9. Bouwindustrie en bouwconstructie, aanneming

10. Steen, aardewerk, glas en kristal

11. Chemische industrie

12. Oliën, vetten en zeepen

13. Textiel en kunstzijde

14. Kleeding

15. Leer en leetbewerking

16. Voedings- en genotsmiddelen
a. Bierbrouwerijen, distilleerderijen en likeurstokerijen
b. Cacao, chocolade en suikerwerken
d. Koek, banket, meel en brood
e. Tabak, sigaren en sigaretten
f. Slachterijen
g. Zuivelbedrijven en melkinrichtingen
h. Diverse voedings- en genotsmiddelen

17. Papier en carton

18. Grafische bedrijven, met inbegrip van uitgeverij

19. Gas, electriciteit en water (met inbegrip van bijzondere distributie-bedrijven)

20. Diverse industrieele bedrijven

VI. Handel

1. Algemeen

2. Algemeene import, export, agentuur en commissle

3. Grossierderij 

4. Warenhuizen en winkelzaken
5. Graan
6. Hout
7. Papier
8. Koloniale producten
9. Diverse handelsbedrijven w.o. exploitatie van onroerende goederen

VII. Transport en andere dienstverleening

1. Algemeen

2. Spoorwegen

3. Tramwegen

4. Scheepvaart

5. Luchtvaart

6. Expeditie en algemeen transport, autodiensten

7. Veemen, entrepōts en pakhuizen

8. Post, telegraaf en telefoon, giro

9. Kanaalmaatschappijen

10. Diverse dienstverleeningen

VIII. Hotels, restaurants en ziekenhuizen

IX. Verzekering

1. Algemeen

2. Levens- en volksverzekering

3. Brand- en inbraakverzekering

4. Ongevallenverzekering, ziekteverzekering

5. Zee- en transportverzekering

6. Diverse verzekeringen

\title{
$X$. Financieringsinstellingen
}

1. Algemeen

2. Algemeene banken

3. Middenstandsbanken

4. Hypotheek- en scheepsverbandbanken

5. Boerenleenbanken

6. Landbouw-, cultuur- en koloniale bothken

7. Spaarbanken, -fondsen en -kassen, bouwkassen

8. Administratie-kantoren

9. Effectenzaken

10. Voorschot-, disconto- en afbetalingsbanken

11. Diverse financieringsinstellingen w.o. industriebanken

\section{REPERTORIUM VAN LITERATUUR OP HET GEBIED VAN ACCOUNTANCY EN BEDRIJFSHUISHOUDKUNDE ${ }^{1}$ )}

\section{TIJDSCHRIFTENREPERTORIUM}

\author{
Redactie: Centrale Documen- \\ tatiedienst inzake be- \\ drijfsorganisatie N.V. \\ (C.D.B.)
}

\section{A. ACCOUNTANCY}

\section{Lord Plender}

\section{ALGEMEEN}

Redactie - Vrij uitvoerige levensheschrijving van Lord Plender naar aanleiding van diens overlijden op 19 Januari 1946. A I

The Accountant 26 Jan. 1946

06

1) De letters en cijfers links onder de annotaties verwijzen naar den M.A.B.-code, de getallen rechts onder naar den C.D.B.-code. Voor verdere gegevens over den M.A.B.-code zie Systematiek van de Repertoria in dit nummer, voor verdere gegevensover den C.D.B.-code wende men zich tot den C.D.B., Waldeck Pyrmontlaan 25, Amsterdam-Z.

$\mathrm{m} \mathrm{a} \mathrm{b}$ blz. 76 